\title{
La quête de la perfection esthétique et édénique dans: "Le joujou du pauvre" de Charles Baudelaire
}

\author{
Présenté par \\ Dr Riham Alaa Raafat \\ Maître de conférences à la faculté de Pédagogie \\ Université de Damanhour \\ مجلة الدراسات التربوبية والانسانية ـ كلية التربية ـ جامعة دمنهور \\ المجلد الثانى عشر - العدد الرابع - لسنة 2020
}




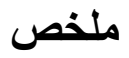

السعي وراء الكمال والجمال في نص "لعبة الفقير" للكاتب شارل بودلير:

يتناول البحث اشكالية التضامن الاجتماعي بين الفقراء والأغنياء والبحث عن الجمال

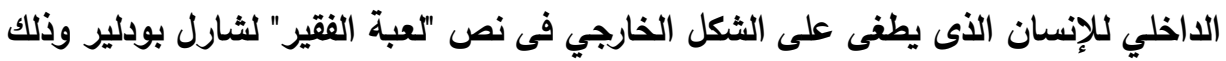

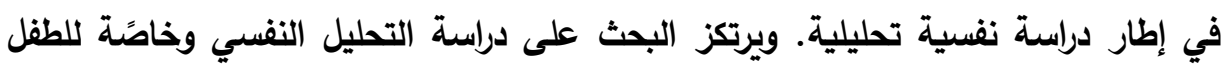

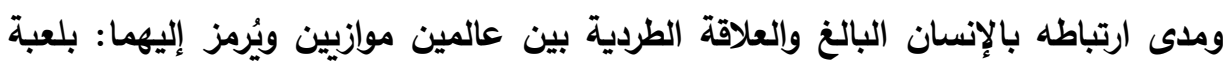

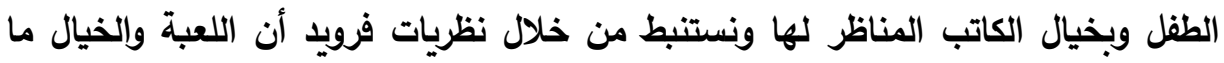

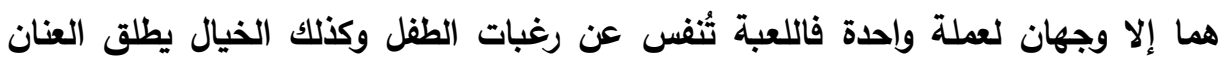

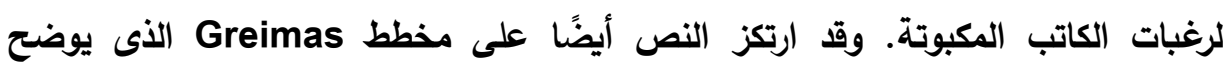
العلاقة بين الثخوص في السرد النصي فالطفل الفقير هو البطل التي تدور حوله الأحداث

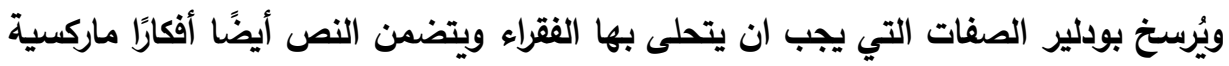

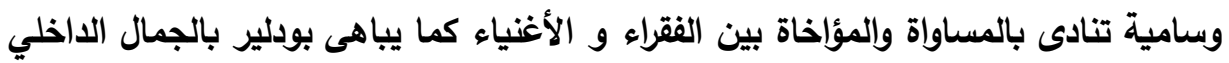

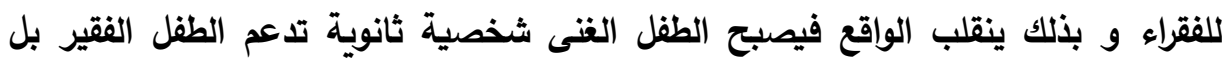

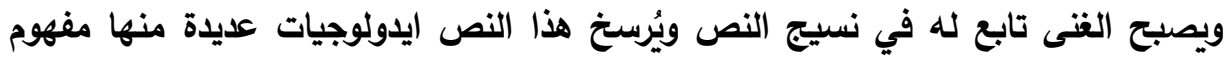

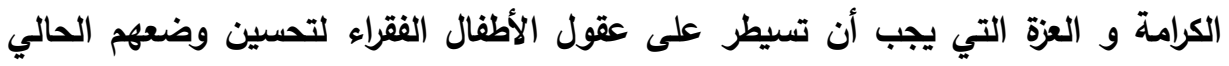

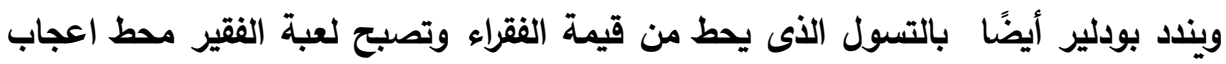

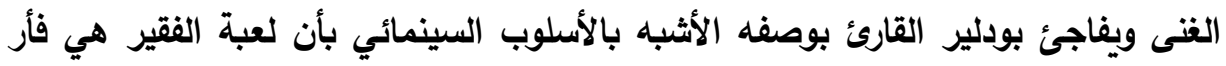

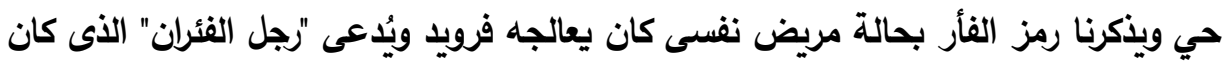

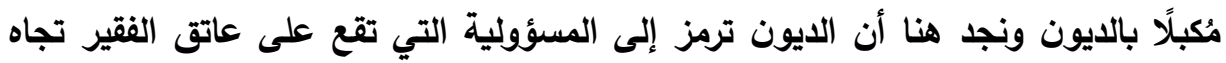

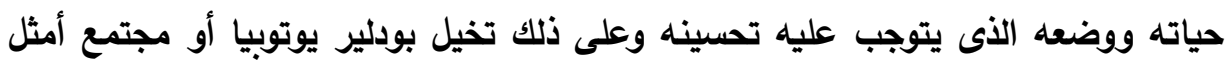

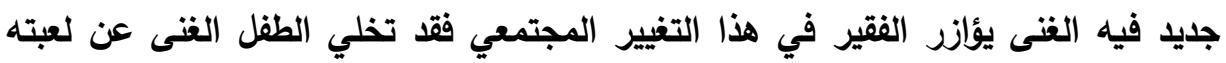

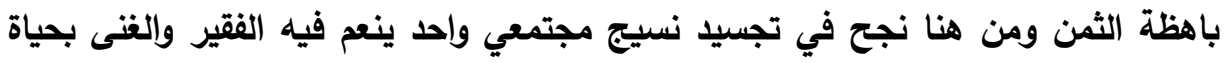

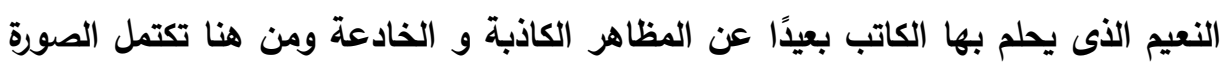

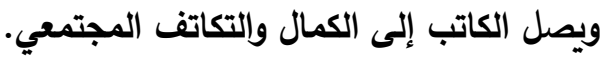




\section{La quête de la perfection esthétique et édénique dans: "Le joujou du pauvre"1 de Charles Baudelaire}

Le symbole "était, chez les Grecs, un morceau de bois ou un osselet qui avait été coupé en deux et dont deux familles amies conservaient chacune une moitié en la transmettant à leurs descendants. Lorsque plus tard ceux-ci rapprochaient les deux fractions complémentaires et parvenaient à reconsti/tuer l'unité brisée dont elles étaient issues, ils redécouvraient ainsi une unité perdue mais retrouvée ${ }^{2}$

D'ordinaire, l'être poétisant tisse un réseau de signifiants pour promulguer un nouveau credo artistique qui lui appartient exclusivement. A l'instar de Janus dieu à double face $^{3}$, Baudelaire semble avoir deux postulations tournées en sens contraires : l'une orientée vers Dieu et l'autre vers Satan. Il en découle une dimension duale qui jouxte le beau et le laid, le pauvre et le riche, le donateur et le donataire, le physique et le psychique... Cette duplication concorde avec l'onomastique du poète, puisque l'étymologie grecque du

1 BAUDELAIRE, Charles, Le joujou du pauvre, in Morale du joujou de l'essence du rire, la bibliothèque numérique romande, 1853-1869, pp.3-4, consulté sur:

https://ebooks-bnr.com/ebooks/pdf4/baudelaire_joujou_essence_rire.pdf, le 20/5/2020

${ }^{2}$ GARRIGUES, Pierre, Poétiques du fragment, KLINCKSIECK, Esthétique, paris, 1995, p.131

3 SCHMIDT, Joël, Dictionnaire de la Mythologie grecque et romaine, Larousse, Paris, 1985, p.108 
nom Charles Ker signifie le lieu commun qu'on habite. ${ }^{4}$ S'agit-il d'une terre promise, d'une utopie tissée par le fantasme baudelairien ou d'un monde parfait où tout être est dignement acclamé, d'autant plus que «le beau» de la perfection résonne dans le Bau de Baudelaire, et paraît puiser ses ressources dans «le laid» qui se répercute dans la finale « lai », constituant ainsi les deux pôles d'une parenthèse qui renferme l'être poétisant Bau/de/lai/. Aussi le nom de Baudelaire pourrait-il être transcrit en «beau de l'air $»^{5}$. Le paradis perdu serait-il donc une trouvaille ensevelie dans l'univers poétique où tout désir cherche son assouvissement et son exaucement ? Ce rêve de perfection transmue le monde clivé du poète en évasion qui cherche à pallier toute tare, et communiquer aux hommes la vision extatique du beau. Ce cosmos à double portes semble miser sur le rythme binaire, c'est dans ce sens que le lisible et le visible, le dit et le nondit, le figuratif et le descriptif, le joué et le sacralisé, le somatique et le psychique, le gestuel et le sensuel... bref tout duo lyrique, le poète semble le soumettre à une harmonie particulière lui permettant de retrouver le monde édénique de l'enfance. Il semble donc que Baudelaire ne cesse de détecter les fluctuations de cette enfance qui le consume allant de la phase archaïque ${ }^{6}$ jusqu'à la phase phallique. ${ }^{7}$ Il traîne une quête où l'enfant qui se voit perdu et délaissé trouve son image spéculaire s'en formant une osmose d'un seul univers. Cette spéculation se laisse voir dès le titre: Le joujou $d u$ pauvre.

4 BOUCRAND-HECQUET, Paul, Dictionnaire étymologique des noms propres d'hommes, Victor Sarlit, Paris, 1868, p.44, consulté sur le site: http://gallica.bnf.fr/ark:/12148/bpt6k65497229, le 29/6/2020

5 Suite de notes qui compose une mélodie.

${ }^{6}$ Cf., Infra celle de l'absence de la mère, du stade du miroir et des réminiscences de l'enfance.

${ }^{7}$ Cf., Infra la symbolique du rat et la connotation phallique.

99 
Prémonition d'une double présence d'un "je", le jumelage titrologique de la syllabe: "jou" fait partie d'un langage infantile, d'une transposition dans un monde lilliputien ; ainsi le narrateur semble s'immiscer tel un Gulliver dans le monde des enfants où tout se conjugue à l'enfance. De plus, ce mot constitué d'une même syllabe multipliée par deux "jou/jou" renvoie au caractère itératif des enfants. Le segment "jou" coïncide avec l'impératif "joue" qui se démarque par un appel à "faire" à l'enfantin". Ce duplicata syllabique "jou" laisse inférer un fusionnement de deux moi ${ }^{8}$. Or ce "joujou" serait en possession d'un seul enfant, imprévisiblement démuni. Alors cette possession normalement pourvoyeuse de suprématie, prête-t-elle à équivoque? Cherche-t-elle à bouleverser l'ordre social ? A fortiori le petit jouet se mue en un sujet-objet en corrélation avec un actant désigné par son rang social modeste. L'ellipse du mot "enfant" semble indispensable pour dépouiller l'actant de son individualité et le couvrir d'anonymat et d'opacité déconcertantes. Par contre le désignatif le pauvre incarne un clan baptisé prolétariat, lequel devient catégoriquement un personnage de premier ordre briguant la place des héros classiques riches et beaux. ${ }^{9}$ Le cosmos du "peu " et du "petit" ${ }^{10}$ semblent corollaires et associables. De ce fait, la dialectique nécessité/ possession se répercute implicitement par la présence du pauvre héros.

Le poète, quant à lui, s'investit dans la diégèse par un "Je" $\mathrm{du}$ moraliste: "Je veux donner l'idée d'un divertissement

${ }^{8}$ Le titre anticipe une dualité qui s'affirme au fur et à mesure par la présence de deux enfants issus de deux mondes parallèles.

${ }^{9}$ La pauvreté aurait un autre visage dans le texte baudelairien. A l'exemple de la mythologie grecque, la Pauvreté connue sous le nom de Pénia, s'unit à Poros pour donner le jour à Eros, l'Amour. Cf., SCHMIDT, Joël, Op.cit., p.150.

${ }^{10}$ Le peu et le petit sont inférés par les substantifs pauvre et joujou révélant subrepticement les traits référentiels de l'actant. 
innocent $^{\prime 11}$. Il serait donc focalisateur interne ${ }^{12}$. En outre, l'ellipse de "vous" montre que Baudelaire énonce un aphorisme à un lecteur virtuel effacé, un "vous" présupposé, un Autre hors champ. L'interlocuteur serait donc générique, imprévisible et invisible situé à l'autre côté du miroir. Du coup, le "je" de l'être poétisant se subvertit en un destinateur ${ }^{13}$ dont les recommandations seraient un point d'appui imprédictible en faveur du Ça, de l'euphorie et du désir dits "innocent". Le dédoublement synonymique : "divertissement" et "amusements" constitue une relation triplée avec le joujou. Ce trio juvénile de l'euphorie paraît réconcilier les trois instances du psychisme narratoriel. "Lorsque le Moi revêt les traits de l'objet, il semble chercher à s'imposer à l'amour du Ça, à le consoler de sa perte"14 et cherche par ricochet à se réconcilier avec le Surmoi car il "remplit la même fonction de protection et de salut que le père, la Providence ou plus tard, le sort"15, nous explique Freud.

Le syntagme nominal: "divertissement innocent" retentit en se convertissant en phrase négative : " Il y a si peu d'amusements qui ne soient pas coupables". La répétition

${ }^{11}$ BAUDELAIRE, Charles, Le joujou du pauvre, Op.cit., p.3

${ }^{12} \mathrm{La}$ focalisation s'avère interne lorsque le foyer est placé dans la conscience d'un sujet témoin qui restreint les informations au point de vue d'un personnage (c'est alors "par ses yeux" que nous vivons la scène). BERGEZ (D.), GERAUD (V.), RODRIEUX (J.J), Vocabulaire de l'analyse littéraire, Dunod, Paris, 1994, p.100

${ }^{13}$ Le destinateur est celui qui demande que la jonction entre le sujet et l'objet soit établie. De plus, "c'est le mandateur qui charge le héros d'une mission", in GREIMAS, Algirdas Julien, La sémantique structurale, PUF, Formes sémiotiques, Paris, (1986), 2007, p.178

${ }^{14}$ FREUD, Sigmund, Le moi et le ça, document produit en version numérique par Gemma Paquet, les Classiques des sciences sociales, Edition électronique, Québec, Macintosh, 2002, , p.22,consulté sur le site: http://classiques.uqac.ca/classiques/freud sigmund/essais de psychanalys e/Essai 3 moi et ca/Freud le moi et le ca.pdf, le 27/6/2020

${ }^{15}$ Ibid., loc.cit.

101 
montre la réversibilité du langage. Cet infléchissement morphologique, marqué formellement par un glissement de l'assertion vers la négativité, renvoie à une dénégation de la culpabilité. Ainsi, l'innocence semble déculpabiliser à première vue le moi narratoriel ${ }^{16}$ et ce, via le duo assertion /négation nouant une relation de parasynonymie biphasée et complémentaire. Toujours est-il que la répétition comme l'a déjà démontrée Freud est un moyen de décharge du Ça, car au fond, l'enfant qui s'acharne à revivre une fois de plus les moments euphoriques déjà vécus cherche à les maîtriser et en ressentir le même plaisir déjà goûté ${ }^{17}$.

Or la dualité sémique "innocent" et "coupable" met l'accent sur l'inhérence d'une controverse inéluctable : tout désir serait-il subséquemment convertible en instance culpabilisée ? $^{18}$ Goldberg avait déjà assimilé la culpabilité au désir en précisant qu'il y a «une sorte de contradiction interne qui rend le désir à la fois nécessaire et impossible $\gg^{19}$ Du coup, l'intention serait en amont et en aval inculpée et accusée et l'impulsion infligerait un châtiment à tort ou à raison au Moi. En d'autres termes, le Surmoi qui conçoit le désir même innocent comme prohibé voire répréhensible

${ }^{16}$ Le Moi du poète se voit voué à assumer un rôle explicitement innocent et ce, en orientant le sujet présupposé vers une idéologie épistémique ou même vers un adage.

${ }^{17}$ FREUD, Sigmund, Au-delà du principe de plaisir, document produit en version numérique par Gemma Paquet, Classiques des sciences sociales, Edition électronique, Québec, Macintosh, (1920), 2002, p.33, consulté sur le site:

http://classiques.uqac.ca/classiques/freud sigmund/essais de psychanalys e/Essai_1_au_dela/Au_dela_principe_plaisir.pdf, le 27/3/2020

${ }^{18} \mathrm{Le}$ va-et-vient entre déculpabilisation et culpabilisation montre d'une part que le désir est conçu comme impossible et interdit et d'autre part, qu'il semble porter à son insu une idée subversive.

${ }^{19}$ GOLDBERG, Jacques, La culpabilité: axiome de la psychanalyse, PUF, Nouvelles voix en psychanalyse, Paris, 1985, p.13 
مجلة الدراسات التربوية والانسانية ـ كلية التربية ـ جامعة دمنهور ـ المجلد الثانى عشر - العدد الرابع - لسنة 0202

punit avec la même intransigeance non seulement la réalisation, mais aussi la simple intention. ${ }^{20}$

Baudelaire, en être actantiel interpelle ostensiblement son sujet ${ }^{21}$ dans la phrase : "Quand vous sortirez le matin avec l'intention décidée de flâner sur les grandes routes ». Le "je" de l'incipit s'adresse à un "vous", puis s'efface pour se débarrasser de toute détermination psychologique et tourne en un "être" témoin. Est-ce que Baudelaire renonce à son pouvoir qui se transmue en un simple vouloir ? Le moi baudelairien assigne à l'interlocuteur "vous" son rôle actantiel pour l'interposer dans le réseau narratif en tant que son ombre ou son propre reflet. Dans ce sens le verbe "sortir" promeut le "vous" en personnage-personne extraverti dirigé vers un monde inconnu, le verbe "flâner" marque un déplacement erratique, un égarement hors de son cosmos, voire un anéantissement de soi. Constat qu'a déjà démontré Garrigues dans son ouvrage Poétiques du fragment: "La dérive du sujet est une Odyssée labyrinthique, une errance dont le héros n'est personne, comme Ulysse [...]"22 La chronographie "le matin" et la topographie au pluriel "sur les grandes routes" dénotent une libre circulation embrassant l'espace et le temps sans toutefois dépasser l'ordre du désir ou même celui de l'intention.

L'être poétisant se transcende à son tour et passe pour un être supérieur qui ordonne son interlocuteur tout en restant dans l'angle mort. Dans la phrase, "remplissez vos poches de petites inventions à un sol", l'impératif "remplissez» et le

${ }^{20}$ MENDEL, Gérard, La psychanalyse revisitée, La découverte/Poche, Paris, 1998, p.73

${ }^{21}$ Le sujet est ce qui est orienté vers un objet. En d'autres termes, c'est "quelqu'un qui fait l'action", in GREIMAS, Algirdas Julien, Opc.cit., p.173

${ }^{22}$ GARRIGUES, Pierre, Op.cit., p.397

103 
terme « vos poches » reflètent une idée subversive ${ }^{23}$, un appel à dissimuler des objets, à garder en-deçà de soi une intention, une provocation. Solliciter ses interlocuteurs à dissimuler dans leurs poches un objet, révèle un désir de les manipuler et ce, en les encourageant d'agir impulsivement à l'insu des autres. Aussitôt, cette alternance entre apparition/dissimulation fait écho à la dialectique être/ paraître. Le contenant et le contenu sont donc discordants. Le paraître représente les poches et l'être reflète les objets dissimulés ${ }^{24}$. En outre, la synonymie kaléidoscopique du mot joujou se trouve quadruplée avec astuce et en filigrane par: divertissement, amusements et inventions pour mettre en relief la subversion du jeu d'enfant en un fantasme inavoué d'un adulte. Or, chiffre de la construction parfaite, le 4 est inhérent à l'onirisme de la perfection esthétique. ${ }^{25}$ "Châteaux en Espagne ou rêves éveillés" 26 , nous dit Freud qui a déjà relevé ce duplicata jeu/fantasme dans son ouvrage intitulé : La création littéraire et le rêve éveillé. Il précise en outre, que contrairement à l'enfant qui ne cache pas ses fantasmes et joue devant l'adulte, ce dernier en ressent une honte profonde et tient à les dissimuler: "il préférerait avouer ses fautes que

${ }^{23}$ Cf., Supra la note où le va-et vient entre culpabilisation et déculpabilisation s'affirme en tant qu'idée bouleversant l'ordre.

${ }^{24}$ Cf., Infra ce décalage résonne à la dialectique être/ paraître des enfants riche et pauvre.

${ }^{25}$ CHEVALIER, Jean et GHEERBRANT, Alain, Dictionnaire des symboles, Robert Laffont, Bouquins, Paris, (1969), 1982 pour l'édition consultée, pp.796-797

${ }^{26}$ FREUD, Sigmund, La création littéraire et le rêve éveillé, document produit en version numérique par Jean Marie Tremblay, les Classiques des sciences sociales, Edition électronique, Québec, Macintosh, (1933), 1971, p.7, consulté sur le site:

http://classiques.uqac.ca/classiques/freud/04 creation_litteraire/creation 1 itteraire.pdf,le 27/4/2020 
مجلة الدراسات التربوية والانسانية ـ كلية التربية ـ جامعة دمنهور ـ المجلد الثانى عشر - العدد الرابع - لسنة 0202

de faire part de ses fantasmes. ${ }^{27}$, affirme le célèbre psychologue.

Parallèlement, le terme "inventions" symbolise l'insatisfaction des circonstances actuelles. ${ }^{28}$ Le poète exhorte son mandataire à donner aux pauvres des inventions à une valeur modeste tout en restant à l'abri du regard. Tenez le bâton par son milieu serait donc la vraie intention du poète préconisant que les objets coûtent le minime. Un sol est la monnaie archaïque qui rappelle un déjà passé consistant dans le vécu de Baudelaire. Le souvenir d'enfance semble se répéter dans l'imaginaire baudelairien se créant un monde à l'instar de l'enfant qui joue. ${ }^{29} \mathrm{Du}$ coup, le don se mue en événement intense qui éveille chez le poète une scène infantile, sorte de souvenir-écran qui le ramène à l'image de sa mère. Toujours est-il que les termes divertissement et amusements se subvertissent en petites inventions, paradigme qui engendre une conversion duale. Aussi Intention/inventions seraient-ils deux paronymes subversifs marquant le parcours allant du psychisme vers le credo baudelairien. La lettre $T$ se révélant comme vocation ou mission $^{30}$ tourne en $V$, lettre aux pouvoirs médiumniques qui symbolise la voie à prendre pour arriver à la Victoire ${ }^{31}$. De même, le plaisir, représenté par les termes au masculin joujou,

${ }^{27}$ Ibid., p.6

${ }^{28}$ Cf., KURTH, Hanns, Dictionnaire des rêves de A à Z, France Loisirs, Paris, 1977, p.211 consulté sur: http://ekladata.com/1Dj_10Y2_eJFI99NAflZdFi9_Vg/Dictionnaire-DesReves-De-A-a-Z.pdf, le 13/5/2020

${ }^{29}$ Le jeu est conçu comme "un faire signifiant" qu'on peut comparer à la poésie. Cf, DIEZ, Verónica, "Le jeu chez l'enfant comme lecture et figuration d'un invisible", Recherches en Psychanalyse [en ligne], 12/2011, mise en ligne le 22 décembre 2011, p.2

${ }^{30}$ Cf., http://arithmomancie.exoteric.fr/numerologie/signification-deslettres/lettre-t/article622.html, le 17/5/2020

${ }^{31}$ Cf., http://www.ma-numerologie-gratuite.com/lettres/lettre-V.html, le $17 / 5 / 2020$

105 
divertissement et amusements, tourne en des jouissances exprimées par un nom au féminin pluriel inventions. Alors il en découle une entrevision d'une image taboue de la femme, un ersatz de l'imago ${ }^{32}$ de la mère car en principe la figure métonymique de la mère s'investit clandestinement dans les désirs extravertis et élaborés du Moi, comme le précise Mendel qui ajoute que : «le sujet, identifiant inconsciemment le monde extérieur à la mère, reporte sur ce monde extérieur une ambivalence foncière qui le paralyse. $»^{33}$

Pour combler le vide parental et compenser l'absence maternelle ${ }^{34}$ dans le stade du miroir, le sujet cherche à suppléer le manque par des "objets transitionnels" "ou par "des jouets" 35 . Ces inventions font écho aux souvenirs d'enfance de Baudelaire ${ }^{36}$. Selon Freud, «l'homme adulte se

${ }^{32}$ Nomenclature adoptée par Mendel in MENDEL, Gérard, Op.cit., p.183

${ }^{33}$ MENDEL, Gérard, Op.cit., p. 170

${ }^{34}$ L'absence maternelle est surtout reflétée par la problématique œdipienne désignée par "l'interdit premier" Cf, GOLDBERG, Jacques, Op.cit., p.12 Constat qui coïncide avec la barrière baudelairienne qui semble rompre le rapport mère/fils vu le remariage de sa propre mère lors du décès de son père. D'ores et déjà sa mère paraît comme un « interdit premier »

35 MENDEL, Gérard, Op.cit., p.127 Cette phase est celle du premier destinataire, le donataire auquel, Baudelaire cherche à confier les rôles de son jeu à un sujet mandataire.

${ }^{36}$ Le rapport jouet/fantasme dérive en effet d'un épisode mnésique. Baudelaire enfant était invité à recevoir un jouet. Il choisit alors le plus cher, mais sa mère le contraint à renoncer à son désir et à prendre le plus modeste. Baudelaire opte pour le juste-milieu dans un autre fragment intitulé Morale $d u$ joujou: «Avec cette admirable et lumineuse promptitude qui caractérise les enfants, chez qui le désir, la délibération et l'action ne font, pour ainsi dire, qu'une seule faculté, par laquelle ils se distinguent des hommes dégénérés, en qui, au contraire, la délibération mange presque tout le temps, - je m'emparai immédiatement du plus beau, du plus cher, du plus voyant, du plus frais, du plus bizarre des joujoux. Ma mère se récria sur mon indiscrétion et s'opposa obstinément à ce que je l'emportasse. Elle voulait que je me contentasse d'un objet infiniment médiocre. Mais je ne pouvais y consentir, et, pour tout accorder, je me résignai à un juste-milieu », BAUDELAIRE, Charles, 
مجلة الدراسات التربوية والانسانية ـ كلية التربية ـ جامعة دمنهور ـ المجلد الثانى عشر - العدد الرابع - لسنة 0202

souvient du grand sérieux avec lequel il s'adonnait à ses jeux d'enfant, et il en vient à comparer ses occupations soi-disant graves à ces jeux infantiles [...] $»^{37}$

Baudelaire énumère les trois inventions cachées dans les poches du sujet : "Le polichinelle plat mû par un seul fil, les forgerons qui battent l'enclume, le cavalier et son cheval dont la queue est un sifflet». Polichinelle, ce personnage caricatural de la commedia dell'arte italienne connu par son caractère braillard et irrespectueux des codes sociaux ${ }^{38}$, symboliserait l'instance du Ça réceptacle des désirs, lequel est domptable, quoique, mû par un seul fil. ${ }^{39}$ Le Ça est subséquemment exhorté à modérer ses penchants, comme l'a déjà démontré Nietzsche en considérant le fil d'Ariane comme un outil que "la jeune femme [Ariane] utilisa pour sortir de sa prison aux multiples sentiers et impasses: le fil d'Ariane est l'image de la raison qui toujours triomphe ${ }^{40} \mathrm{Du}$ pathos raisonné, nous passons au logos non-émotionnel. Les forgerons qui battent l'enclume incarneraient le Surmoi ou les gardiens qui punissent le coupable et protègent le Ça des dangers externes. ${ }^{41}$ Reste le cavalier et son cheval dont la queue est un sifflet, lesquels semblent représenter le Moi équilibré qui domine ses instincts et concilie son Moi-idéal. Ce cavalier faisant corps avec sa monture se crée une osmose

Op.cit., p.6 ce juste-milieu serait d'ores et déjà le dogme baudelairien. (nous soulignons)

${ }^{37}$ FREUD, Sigmund, La création littéraire et le rêve éveillé, Op.cit., p.5

${ }^{38}$ FOUREZ, Florence, «Secret de Polichinelle », in Le point.fr, 8/11/2011 consulté sur: https://www.lepoint.fr/debats/secret-de-polichinelle-08-112011-1394132_2.php, le 21/5/2020

39 Ce fil s'oppose au fil d'Ariane qu'elle avait fourni à Thésée son mari pour l'empêcher de s'égarer dans le Labyrinthe en allant tuer le Minotaure. Cf., SCHMIDT, Joël, Op.cit., p.23

${ }^{40}$ Cf., Ibid., pp.23-24

${ }^{41}$ Le Surmoi tend à assumer le double rôle providentiel et paternel consistant à décréter la loi et à infliger les sanctions au Moi.

107 
où le Moi console le Ça. Or la queue du cheval tourne en un sifflet, i.e., en objet qui alerte. Ce changement d'état reflète la subversion d'Eros en Thanatos d'où l'omniprésence du Surmoi et ce, dans la queue du cheval ${ }^{42}$. Constat qui coïncide avec l'idée freudienne admettant que l'instinct de mort a "pour fonction de ramener tout ce qui est doué de vie organique à l'état inanimé. ${ }^{43}$

La superposition trilogique des joujoux coïncide avec la taxinomie triadique du psychisme humain allant jusqu'au juste-milieu, à l'équilibre psychique des donataires dits des destinataires. La superposition et l'égalité des trois instances ${ }^{44}$ sont reflétées par le schéma ci-dessous:
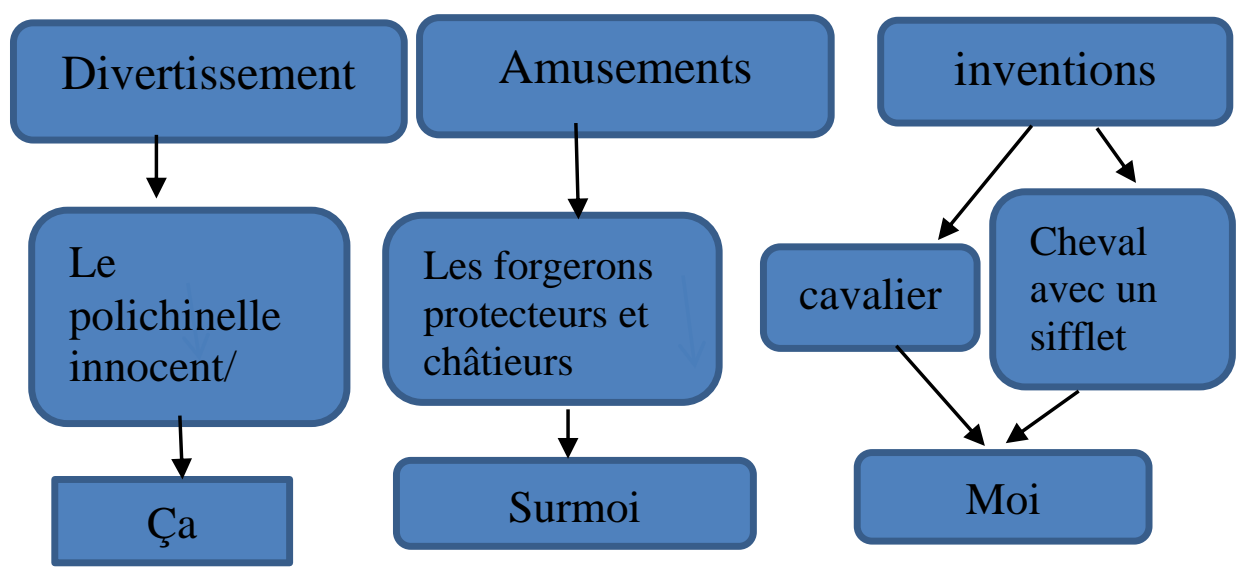

Cette désignation triplée des joujoux qui s'étale sur trois lignes se démarque par l'idée de la plénitude des poches. Le paradoxe entre le lieu clos et le lieu ouvert "Et le long des cabarets, au pied des arbres" va de pair avec l'idée de la

${ }^{42}$ Le fait que le Surmoi fasse partie du corps animalier lui assigne un rôle conciliateur avec le Moi.

${ }^{43}$ FREUD, Sigmund, Le moi et le ça, Op.cit., p. 31

${ }^{44}$ Nous remarquons que les désignations du mot joujou sont situées symétriquement avec les inventions dont chacune équivaut à une instance psychique quasi modérée. 
مجلة الدارات التربوية والانسانية ـ كلية التربية ـ جامعة دمنهور ـ المجلد الثانى عشر - العدد الرايع - لسنة 0202

flânerie et du parcours. Dans la phrase "Faites-en hommage aux enfants inconnus et pauvres que vous rencontrerez", Baudelaire semble simplifier les dons en un pronom personnel "en " cherchant toujours à dissimuler cet acte charitable $^{45}$, car selon lui, le don sert implicitement à vénérer les enfants pauvres et anonymes. Leur incognito est cooccurrent avec l'asile au pied des arbres où les êtres démunis habitent, ainsi leur rencontre avec le sujet serait régie par le hasard. Partant, le parcours du mandataire qui est amorcé par un acte intentionnel tourne en un vrai faire et se termine par la phase de l'attente reflétée par l'image spéculaire "vous verrez. leurs yeux".

Faites-en hommage aux enfants inconnus (action)

remplissez vos poches vous verrez leurs yeux

(intention) (répercussion)

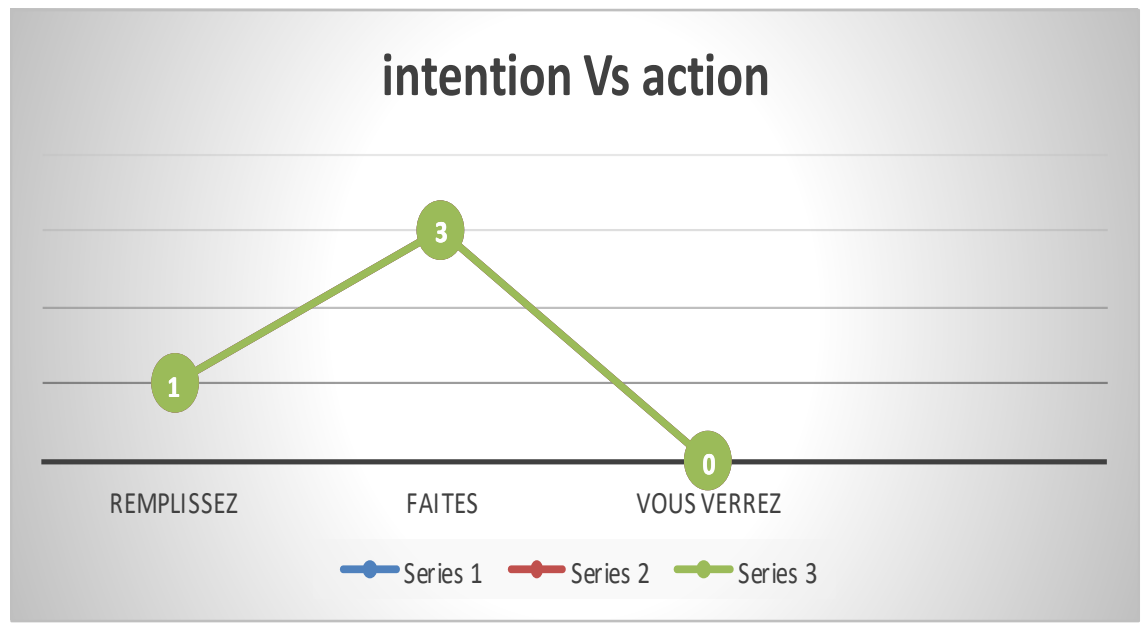

${ }^{45} \mathrm{Ce}$ don semble coïncider avec les idées subversives que Baudelaire tente d'inculquer dans l'esprit des futurs insurgés, et de ce fait, il éveille la dignité des pauvres. Il assumerait le rôle de Robin des bois qui assure l'équité sociale en fournissant discrètement des dons aux pauvres sans pour autant les ôter aux riches. 
L'infléchissement de l'intention vers l'action s'avère injonctif. En revanche, le résultat spéculaire "vous verrez" marque depuis lors la passivité totale du sujet qui attend la réaction des pauvres donataires. Le futur accentue cette phase d'attente et de réception. L'image des petits enfants se réduit métonymiquement en des yeux qui s'agrandissent démesurément allant de pair avec la grandeur incommensurable du désir. Vous devient le focalisateur oculaire qui contemple le miroir de l'inconscient, lieu de recel du refoulé des démunis. Tel est donc un moment de silence, une rupture où les yeux sont désormais les vrais actants. Mais la réponse serait l'avidité et le désir qui remontent à l'instance du conscient, à l'instant enchanté où le dialogue est nonverbal et visuel. Cet échange tourne en une négation de l'action. "Ils n'oseront pas prendre" et l'ellipse du don soulignent que le désir leur paraît interdit et convertible en représentation prohibée et inculpée. Cette négation infléchit vers une affirmation douteuse mais possible rend le bonheur probable voire réalisable. Selon Mendel, il "leurre d'abord l'insatisfaction" ${ }^{46}$. Ce laps de temps inerte tourne en action. $\mathrm{Du}$ regard muet, nous passons au contrecoup gestuel. Le segment phrastique "Puis leurs mains agripperont vivement le cadeau" marque la deuxième phase qui succède au non-agir. Mais cette étape paraît régie par l'inconscient car la main semble transgresser l'ordre du logos comme l'a déjà démontré MESSINGER qui définit le geste manuel comme une:

"trahison corporelle? L'esprit et le corps ne partagent pas toujours le même point de vue. La manière dont les mains chorégraphient leur rôle

${ }^{46}$ Cf, Supra MENDEL, Gérard, Op.cit., p.145, le désir est conçu répréhensible selon la théorie de Mendel. 
مجلة الدارات التربوية والانسانية ـ كلية التربية ـ جامعة دمنهور ـ المجلد الثانى عشر - العدد الرابع - لسنة 0202

est à la fois un code d'intention et un refrain gestuel." ${ }^{147}$

Baudelaire choisit le mot cadeau pour achever l'aspect quinconce de la désignation du mot joujou. Le symbolisme quintuple se révèle comme le nombre fondamental «des sociétés secrètes ${ }^{48}$ et de la "quint-essence" $[\mathrm{Sic}]^{49}$. De même, "Chez les Aztèques, le dieu cinq [...] est le maître de la danse et de la musique. Cette fonction apollinienne l'associe à l'amour, au printemps, à l'aurore, et à tous les jeux." ${ }^{50}$ Baudelaire qui désigne le don par le mot cadeau tend à protéger les pauvres contre la moindre humiliation. Aussi le destinateur semble-t-il être improvisé père de la tribu pendant la phase prépubertaire où il se voit voué à leur insuffler la dignité.

L'adverbe vivement dans le segment phrastique : «leurs mains agripperont vivement $\gg$ marque la rapidité de l'action allant de pair avec la fuite: "et ils s'enfuiront comme les chats qui vont manger loin de vous le morceau que vous leur avez. donné, ayant appris à se défier de l'homme".

${ }^{47}$ MESSINGER, Joseph, Le langage des gestes pour les Nuls, First-Gründ, Paris, 2009, p. 169

${ }^{48}$ CHEVALIER, Jean et GHEERBRANT, Alain, Op.cit., p.254, le chiffre 5 est le nombre des branches de l'étoile flamboyante : le symbole de la francmaçonnerie. Ainsi, les sociétés secrètes semblent se rapprocher avec cette organisation. Baudelaire se voit effacé du cadre du mimesis peut-être pour respecter une déontologie équivalente à celle de la tradition maçonnique décrétant que : personne ne parle au nom de la franc-maçonnerie et personne ne l'a fait d'autant plus qu'elle encourage les maçons à penser par eux-mêmes. Cf., BENHAMOU, Philippe et HODAPP, Christopher, La Franc-maçonnerie pour les nuls, First Editions, 2008, p.37

${ }^{49} \mathrm{La}$ quintessence semble se référer à l'évolution biologique et spirituelle de l'homme qui paraît inspirée du processus de la germination du maïs qui sort de la terre le cinquième jour. Cf., CHEVALIER, Jean et GHEERBRANT, Alain, Op.cit., p. 255

${ }^{50}$ Ibid., p. 256

111 
En comparant les enfants pauvres aux chats, Baudelaire les réduit à un état bestial dual, et ce, en leur accordant la douceur et la méfiance féline. Ces petits assimilés aux bêtes sont transposés dans un monde primitif et indépendant. ${ }^{51}$ Guidés par leur instinct, les enfants animalisés envisagent leur cadeau comme un objet consommable. Séduits par un monde sans contrainte, ils se recroquevillent dans une zone ludique enchantée à l'image de celle des gourmandises où l'intuition dit son mot. Ces deux lieux parallèles mènent subrepticement ces créatures à l'assouvissement de leur désir. Rassasier la faim des chats paraît incontournable et corollaire à l'acte de donner des cadeaux aux enfants afin de satisfaire leurs fantasmes. L'hégémonie de l'ordre animal montre que les chats et les enfants cohabitent librement, que les petits en acquièrent l'intuition bestiale, que l'homme adulte est défiant et redoutable. Aussi ce monde lilliputien ne paraît-il ni crédule ni domptable au monde patriarcal lors de cette phase, à savoir la phase prépubertoire.

De l'échange non-verbal procédé par le gestuel, nous passons à une mimesis que nous pourrions décrypter en langage cinématographique où la topographie semble assurer une fonction narrative.

De la technique travelling où la focalisation narratorielle coïncide avec la caméra qui se déplace horizontalement dans l'espace et ce, en filmant le narrataire avec la cohorte des pauvres, nous passons à une inversion du cadre et de la technique cinématographique. La distance focale s'élargit et le narrateur semble adopter un téléobjectif qui permet de filmer de loin en respectant les perspectives. Le zoom lent permet de capter de prime abord un plan d'ensemble, avant de passer au

${ }^{51}$ Cf., Supra la théorie de Mendel qui conçoit le désir comme répréhensible. Ainsi, Baudelaire semble transposer les enfants dans le monde animal pour déjouer l'instance qui culpabilise le désir et de ce fait, il serait dorénavant permis et hors d'atteinte de tout reproche et de toute infamie. 
plan moyen: "Sur une route, derrière la grille d'un vaste jardin, au bout duquel apparaissait la blancheur d'un joli château, frappé par le soleil [...]". La caméra qui se rapproche du sujet filmé va de l'ouvert jusqu'au clos imperceptible. Le repère spatial «Derrière la grille » rend concret l'isolement et l'enfermement. Quant au jardin, il symbolise "la puissance de l'homme et, en particulier, [...] son pouvoir sur une nature domestiquée." 52 Cependant cette richesse marque une perfection imparfaite car les adverbes «derrière » et «au bout» accentuent l'idée de la claustration et du refoulement. Constat qui coïncide avec la théorie de Chevalier et de Gheerbrant qui trouvent dans tout jardin « un symbole de culture opposée à la nature sauvage, du réfléchi au spontané, [...] de la conscience à l'inconscient $»^{53}$.

Ce paysage ayant plusieurs lignes de fuite ${ }^{54}$ se démarque également par une portée impressionniste de clair/obscur car ce château occulte et hermétique éblouit le regard par la blancheur de sa façade. Cette seule évocation chromatique "signifie tantôt l'absence, tantôt la somme des couleurs". Couleur de passage et de changement de condition, le blanc est "un rien plein de joie juvénile ou, pour mieux dire, un rien avant toute naissance, avant tout commencement" 55 L'entrevision de l'image matricielle et maternelle semble resurgir par l'emploi du substantif la blancheur : le premier trait que Baudelaire attribue au joli château. Le paradigme adjectival joli signifiant très agréable à voir ${ }^{56}$ paraît

${ }^{52}$ CHEVALIER, Jean et GHEERBRANT, Alain, Op.cit., p.531

${ }^{53}$ Ibid., loc.cit

${ }^{54}$ Direction de perspective

${ }^{55}$ CHEVALIER, Jean et GHEERBRANT, Alain, Op.cit., p.125

56 https://www.linternaute.fr/dictionnaire/fr/definition/joli/, dictionnaire en ligne consulté le 7/6/2020

113 
révélateur : il démontre la superficialité du plaisir suscité. ${ }^{57}$ La symbolique du repère spatial château accentue l'idée de la protection. Son accès difficile montre a fortiori que « $[. .$.$] ce$ qu'il enferme est séparé du reste du monde, prend un aspect lointain, aussi inaccessible que désirable $\gg .{ }^{58}$ De par les contes de fée, c'est dans les châteaux que «[...] languissent les princes charmants, en attendant [...] la voyageuse éblouissante. ${ }^{59}$ En Psychanalyse, il connote le jumelage des désirs réprimés dans le Ça. Par ricochet, ce réceptacle de rêves est contraint par le Surmoi incarné par le soleil frappant sa façade. Cette lexie astrale est "le symbole du principe générateur masculin et du principe d'autorité, dont le père est pour l'individu la première incarnation [... $]^{160}$. L'inversion du sujet "se tenait un enfant beau et frais" accorde une importance primordiale au paraître de l'enfant plutôt qu'à son être, ce qui laisse inférer sa passivité exprimée par le verbe "se tenait". Du reste, à l'encontre de l'agitation des enfants pauvres ${ }^{61}$, l'image de cet enfant paraît figée. La beauté et la fraîcheur sont attribuées à ce personnage qui garde l'incognito. Sa tenue vestimentaire reflète son rang social. Preuve en est le segment phrastique: [...] habillé de ces vêtements de campagne si pleins de coquetterie. L'isotopie triplée: beau, frais et coquetterie reflète le critérium de la richesse où la beauté physique est associée à la vigueur et à l'élégance et par conséquent ne dépasse pas l'ordre du paraître.

${ }^{57}$ https://www.lalanguefrancaise.com/dictionnaire/definition-joli/, dictionnaire en ligne consulté le 7/6/2020

${ }^{58}$ CHEVALIER, Jean et GHEERBRANT, Alain, Op.cit., p.216

${ }^{59}$ Ibid., loc.cit

${ }^{60}$ Ibid., p.894

${ }^{61} \mathbf{C f}$, Supra les gestes des enfants qui agrippent les cadeaux donnés par le narrateur 
مجلة الدارات التربوية والانسانية ـ كلية التربية ـ جامعة دمنهور ـ المجلد الثانى عشر - العدد الرابع - لسنة 0202

Baudelaire qui noue le duo perceptible beauté/richesse semble subséquemment adresser à son lectant interprétant ${ }^{62}$ une exégèse marquant l'antagonisme entre richesse et pauvreté : "Le luxe, l'insouciance et le spectacle habituel de la richesse rendent ces enfants-là si jolis, on les croirait faits d'une autre pâte que les enfants de la médiocrité ou de la pauvreté ». Le réseau paradigmatique triplé: Le luxe, l'insouciance et le spectacle habituel de la richesse marque l'excès d'ostentation d'une part et la nonchalance d'autre part. Le lexème centripète insouciance préfixé par "in" nie les soucis et rompt avec la double connotation assertive du paraître:

Le luxe et

le spectacle habituel de la richesse

Au luxe qui amorce l'isotopie, s'ajoute le syntagme nominal trilogique et prolixe le spectacle habituel de la richesse qui paraît isomorphe à l'expansion et à la longueur sur l'axe syntagmatique. Image lisible qui assimile la richesse aux apparences, à tout ce qui est visuel, à un paraître d'un être manqué et à un corps sans âme. L'ordre des paradigmes marque la gradation ascendante qui détecte l'accumulation quantitative des lexies.

\begin{tabular}{lll}
\hline Le luxe & l'insouciance & $\begin{array}{l}\text { le spectacle habituel de } \\
\text { la richesse }\end{array}$ \\
Un seul substantif & $\begin{array}{l}\text { Substantif } \\
\text { préfixé et } \\
\text { suffixé }\end{array}$ & $\begin{array}{l}\text { Syntagme prolixe et } \\
\text { triplé }\end{array}$ \\
&
\end{tabular}

${ }^{62}$ Le lectant interprétant essaye d'inférer de sens du récit à travers le message transmis par le personnel romanesque Cf., JOUVE, Vincent, L'effetpersonnage dans le roman, PUF écriture, Paris, 1992, p.190

115 
La pluralité paradigmatique des apparences et celle de l'éblouissement visuel s'associent pour accentuer la joliesse superficielle des enfants. Preuve en est la phrase: «Le luxe, l'insouciance et le spectacle habituel de la richesse rendent ces enfants-là si jolis. » Baudelaire subvertit la beauté en joliesse. Il multiplie une fois de plus la présence de l'enfant beau en y ajoutant les syntagmes des enfants-là si jolis pour mettre l'accent sur l'idée dépréciative de la joliesse superficielle. Il laisse inférer la dialectique individu/collectif en jouxtant le singulier et le pluriel : enfant beau Vs enfants jolis pour insinuer la trivialité de cette communauté riche.

La phrase " [...] on les croirait faits d'une autre pâte que les enfants de la médiocrité ou de la pauvreté" dénote que dans la série racontante, le on de l'énonciation prend la relève intervenant selon Garrigues "comme effet de réel" et de ce fait, il précise que "derrière ces imparfaits, surgit une enfance, à laquelle appartient un sujet, certes masqué, mais présent dans les mots, impliqué en eux". ${ }^{63}$ Cette enfance dédoublée marque par ricochet l'altérité et la dissemblance. Les deux sociétés enfantines sont considérées comme différentes sur les deux plans de l'être et du paraître. Le recours au mot pâte dont la symbolique signifie l'union de l'eau et la terre, du sang et de la chair s'avère finement pertinente. C'est le schème du matérialisme vraiment intime où la forme est évincée, effacée, dissoute. ${ }^{64}$ Aussi, la mollesse et la malléabilité de la pâte sont-elles des traits corollaires à l'enfance. Les enfants sont donc sujets à être modelés. Ils sont chosifiés en des substances pétrissables en phase de préparation.

63 GARRIGUES, Pierre, Op.cit., p.420

${ }^{64}$ CHEVALIER, Jean et GHEERBRANT, Alain, Op.cit., p.734 
مجلة الدراسات التربوية والانسانية ـ كلية التربية ـ جامعة دمنهور ـ المجلد الثانى عثر - العدد الرابع - لسنة 0202

D'autre part, le processus triptyque des rangs sociaux ${ }^{65}$ les rend isomorphes car le terme richesse amorçant le paragraphe semble prendre son écart des autres lexèmes la médiocrité et la pauvreté qui s'alignent côte à côte. De plus, le suffixe té de ces substantifs qui closent le paragraphe laisse résonner leur analogisme. Est-ce que ces deux classes jumelées, associées et alternées par la conjonction de coordination ou diraient le dernier mot? Est-ce que ces deux groupes juxtaposés formeraient la majorité et la masse de la société par rapport à une minorité riche marginalisée dans le monde baudelairien? Y aurait-il un métissage entre médiocrité et pauvreté face à une déréliction de la richesse?

De la série racontante, nous passons derechef à la série racontée et à la mimesis. Le tableau figé de l'enfant riche est parachevé par l'image spéculaire de son joujou. La disposition de l'enfant à côté de son jouet qui lui ressemble rappelle l'effet de la poupée Vaudou. ${ }^{66}$ Le fragment de phrase : «A côté de lui gisait sur l'herbe un joujou splendide » marque l'enterrement de ce dernier. L'inversion verbe/ sujet montre la nouvelle position de ce jouet d'ores et déjà enfoui et abandonné par l'enfant qui cesse d'être son maître dominant.

L'isotopie adjectivale de la description du joujou marque un aspect pléthorique de la richesse. Les traits Splendide, verni, doré, vêtu d'une robe pourpre reflètent l'éclat d'une

65 Il s'agit de l'écart entre le paradigme richesse et le couple médiocrité/ pauvreté jumelé sur l'axe syntagmatique dans cette phrase tirée du Joujou du pauvre: "Le luxe, l'insouciance et le spectacle habituel de la richesse rendent ces enfants-là si jolis, qu'on les croirait faits d'une autre pâte que les enfants de la médiocrité ou de la pauvreté »

${ }^{66} \mathrm{C}$ 'est cette technique de magie noire qui influence à distance l'être à l'aide d'une poupée qui ressemble à l'être subjugué, quoique cette ressemblance se limite au physique. Cf., https://www.dol-celeb.com/objets/poupeevaudou/, consulté le 13/6/2020

117 
poupée. La robe représenterait la mère ${ }^{67} \mathrm{Ce}$ joujou est frais à l'image de l'enfant en chair et en os. La symbolique chromatique pourpre représente la dignité sociale, la royauté et le pouvoir clérical. ${ }^{68} \mathrm{Il}$ en va de même pour l'ornement du joujou « couvert de plumets et de verroteries » où les plumets symbolisent la puissance aérienne. ${ }^{69}$ L'aspect ornemental des plumes reflète un attrait que l'on exerce sur les autres et un attachement incontournable à l'apparence ${ }^{70}$. Les verroteries sont des objets de petits verres colorés ayant un effet spéculaire qui laisse miroiter le superficiel étant donné qu'elles sont de faux bijoux et d'objets de mauvais aloi. Le joujou à l'apparence luxueuse et splendide est donc rejeté et négligé par l'enfant riche. ${ }^{71}$

La satisfaction de l'enfant nanti va au-delà de ses propres cultes, de son monde introverti et de son Surmoi, en témoigne la phrase «Mais l'enfant ne s'occupait pas de son joujou préféré, et voici ce qu'il regardait: » où le regard de l'enfant riche déborde pour voir l'autre côté du miroir. Son insatisfaction l'incite à avoir des fantasmes qui cherchent à le

${ }^{67}$ Ce rejet du joujou splendide fait écho au jeu freudien du Fort-Da qui dénote la réaction puérile face à l'absence/présence de la mère. L'enfant trouve la nécessité de répéter une situation de déplaisir, le moment de la disparition de la mère, c'est en jetant des objets loin de lui que l'enfant prend également satisfaction de la vengeance à l'égard de la mère tout en signifiant à peu près ceci: "oui, oui va-t-en, je n'ai pas besoin de toi, je te renvoie moi-même. Cf., FREUD, Sigmund, Au-delà du principe de plaisir, Op.cit., p.15. De même, ce rejet du jeu fait écho à la phase où l'enfant progresse avançant vers la phase phallique et vers la puberté.

${ }^{68}$ Cf., http://www.1voyance.org/interpretation-reve/themes/les-couleurs-dansles-reves/, consulté le 14/6/2020

${ }^{69}$ CHEVALIER, Jean et GHEERBRANT, Alain, Op.cit., p.768

70 Cf., http://www.dictionnaire-reve.com/interpretation-reve/2341/reve-deplume.html, consulté le 14/6/2020

${ }^{71}$ L'enfant riche a renoncé à son propre monde. Il pourrait être un adjuvant dans le schéma quinaire car il a rompu avec son culte de l'apparence et avec son hégémonie. Cf., Infra où les deux enfants se riaient fraternellement. 
مجلة الدراسات التربوية والانسانية ـ كلية التربية ـ جامعة دمنهور ـ المجلد الثانى عشر - العدد الرابع - لسنة 0202

combler en corrigeant «la réalité qui ne donne pas satisfaction ${ }^{72}$, comme l'explique Freud.

De plus, le segment phrastique: "voici ce qu'il regardait" montre que l'auteur procède par délégation ${ }^{73}$ dans le parcours narratif en transposant un tableau à travers le regard de son personnage. Il s'ensuit donc une mise en abyme où l'instance auctorielle regarde l'enfant qui observe à son tour le monde parallèle. Du cosmos introverti de l'enfant riche, nous passons à un autre univers extraverti. Par le biais du chiasme, Baudelaire laisse inférer la dialectique du dedans/dehors où les lieux font écho aux réflexions spéculaires:

Sur une route, derrière la grille

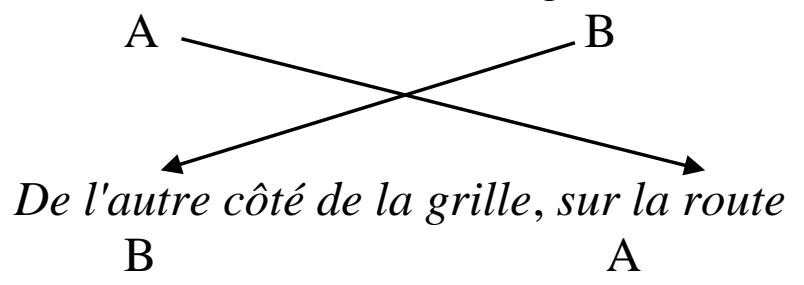

L'article défini dans le repère spatial sur la route marque le glissement de l'imprécision et l'opacité vers l'identifiable. Si le tableau de l'enfant riche est situé dans le cadre inidentifiable et flou "sur une route", ce nouveau monde est reconnaissable à l'instance auctorielle. ${ }^{74}$ L'arrière-plan du nouveau tableau "entre les chardons et les orties" représente le lieu primitif. L'être est assiégé par des plantes sauvages: «le chardon » qui symbolise l'austérité et l'esprit vindicatif. Il

\footnotetext{
${ }^{72}$ FREUD, Sigmund, La création littéraire et le rêve éveillé, Op.cit., p.6

${ }^{73}$ JOUVE, Vincent, Op.cit., p. 12

${ }^{74}$ Le monde du pauvre semble être le cosmos héroïsé par le poète. Baudelaire s'identifie à l'enfant pauvre car sa famille lui impose un conseil judiciaire qui le limite à une rente mensuelle de deux cents francs pour l'arracher à sa nouvelle vie scandaleuse et libertine où le gaspillage de l'héritage paternel menaçait son patrimoine. Désormais il éprouve la tourmente de la misère.
} 
évoque la vertu protégée par des piquants, mais aussi la couronne d'épines de la passion du Christ. ${ }^{75} \mathrm{Il}$ en va de même pour les orties qui piquent tout en gardant leur critère médicinal. Ce monde primitif est assiégé de dangers. En effet, la présence de l'enfant se démarque par son étant, à l'encontre de l'enfant riche qui ne révèle que sa posture figée. Une isotopie quintuple relève le comble de la saleté et de la laideur de l'enfant pauvre en opposition avec le critérium de la beauté et de l'élégance du petit nanti. ${ }^{76}$

Le tableau ci-dessous marque l'antinomie du paraître des deux enfants:

\begin{tabular}{|c|c|c|}
\hline & L'enfant riche & L'enfant pauvre \\
\hline Physique & + & - \\
\hline Santé & + & - \\
\hline Tenue vestimentaire ${ }^{77}$ & + & 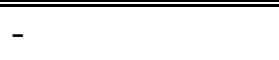 \\
\hline Protection $^{78}$ & + & $+/-$ \\
\hline Beauté $^{79}$ & + & $+1 /-$ \\
\hline
\end{tabular}

75 Cf., https://1001symboles.net/symbole/sens-de-chardon.html, consulté le 18/6/2020, le rôle de l'enfant pauvre ne semble pas seulement héroïsé mais aussi sacralisé par le poète vu les passions et les dangers qu'il encourt.

${ }^{76}$ Cf., Supra l'isotopie triplée de la richesse.

${ }^{77}$ La tenue vestimentaire du pauvre est sa propre robe cutanée noircie par la suie.

78 L'enfant riche est protégé par une nature domestiquée et maîtrisée représentée par la grille du jardin, tandis que l'enfant pauvre est protégé par de mauvaises herbes piquantes ou plutôt une nature sauvage.

${ }^{79}$ La beauté de l'enfant pauvre est vue par un œil impartial. 
مجلة الدراسات التربوية والانسانية ـ كلية التربية ـ جامعة دمنهور ـ المجلد الثانى عشر - العدد الرابع - لسنة 0202

Baudelaire qui distille le beau du laid révèle la beauté de l'enfant pauvre. Le paradigme marmots-parias qui appartient au registre du langage familier est co-occurrent avec le Prolétariat. Sur le plan syntagmatique, Baudelaire semble stipuler la taxonomie du rang social de la pauvreté urbaine consonnant avec la doxa populaire. Dans cette hideur, Baudelaire éveille un charme sur mesure réfractaire au regard générique et humain. Cette beauté inostensible serait patente et perceptible à l'œil considéré comme "un organe de la vision intérieure, et partant une extériorisation de l'œil du cœur". ${ }^{80} \mathrm{Ce}$ beau dans le horrible ne serait perçu que métonymiquement par un œil poétique unique et juste pareil à l'œil divin. ${ }^{81}$ Il semble évacuer l'être de l'enfant pauvre de son paraître. La beauté trouve ses racines dans l'essence et de ce fait, l'apparence est castrée. Constat qui coïncide avec la réflexion freudienne qui conçoit le héros comme un étant décrit du dedans précisant que "c'est dans son âme, en quelque sorte, que réside l'auteur et c'est de là qu'il considère les autres personnages, pour ainsi dire $d u$ dehors ${ }^{82}$ Aussi, l'identification auctorielle au personnage pauvre s'avère-t-elle incontournable et le physique du nanti se révèle-t-il perçu par un regard distancié extradiégétique.

Le duplication lexicale du mot "œil" en procédant par symétrie spéculaire dans la comparaison suivante, accentue l'idée de la subjectivité univoque et ce, en assimilant le lisible au visible et le mot au pinceau: "un oeil impartial découvrirait la beauté, si, comme l'œil du connaisseur devine une peinture idéale sur un vernis de carrossier, il le nettoyait de la répugnante patine de la misère". Baudelaire qui prend la partie du pauvre semble se justifier tout en songeant aux

${ }^{80}$ CHEVALIER, Jean et GHEERBRANT, Alain, Op.cit., p.686

${ }^{81}$ A l'instar de la tradition maçonnique, l'œil symbolise le principe créateur. Cf., Ibid., p.689. Cf., Supra la note du symbole du chiffre 5. ${ }^{82}$ FREUD, Sigmund, La création littéraire et le rêve éveillé, Op.cit., p. 8

121 
métamorphoses du monde des démunis. Il se prend pour un créateur capable de changer le sort des misérables par une retouche ou un vocable. Ainsi la dialectique baudelairienne beau/laid semble stipuler la perfection dans l'utopie du poète où les nuances de la misère seraient aisément gommées.

A l'image de ce monde onirique tracé au pinceau, Baudelaire semble jumeler deux univers antagonistes. Ces deux ailleurs qui puisent dans le réel seraient basculés par des termes subversifs. "Les barreaux symboliques" reflètent un monde réel clivé dont les barreaux sont pourtant irréels. La multiplicité topographique "Deux mondes, La grande route et le château" trace une osmose de deux cosmos étant au même pied d'égalité. En témoigne l'adjectif grande qui confère à la résidence du démuni de la splendeur. Dans le fragment de phrase: "l'enfant pauvre montrait à l'enfant riche son propre joujou, que celui-ci examinait avidement comme un objet rare et inconnu", le principe de réversibilité marque la suprématie $\mathrm{du}$ pauvre dans ce nouveau monde baudelairien ${ }^{83}$. C'est le nanti qui envie le joujou du pauvre. Les qualificatifs "rare" et "inconnu" mettent en valeur ce jouet, en contradiction avec le milieu dépourvu de son possesseur qui lui est désigné par une apparence dégradante de petit souillon rappelant l'idée de la culpabilité. Or, il est souligné que toute saleté et tout péché sont des duplicatas susceptibles d'être purifiés, car au fond, la souillure est due à la soumission répréhensible, à la résignation et à la déréliction des démunis.

Dans son poème Assommons les pauvres ${ }^{84}$, Baudelaire prend la ferme résolution de secouer les passifs et les soumis

${ }^{83}$ L'enfant pauvre devient dorénavant et le sujet et le destinataire car le futur insurgé est mandé par Baudelaire pour assurer la mission de maintenir l'équilibre psychique, de se révolter et de renverser l'ordre social.

${ }^{84}$ BAUDELAIRE, Charles, Assommons les pauvres, in Le spleen de Paris, Bibebook, pp.114-116, consulté sur : 
مجلة الدراسات التربوية والانسانية ـ كلية التربية ـ جامعة دمنهور ـ المجلد الثانى عشر - العدد الرابع - لسنة 0202

de cette communauté-ci, et de discréditer l'acte de l'aumône ${ }^{85}$ : "pour assommer rapidement ce vieillard, je le saisis d'une main par le collet de son habit, de l'autre je l'empoignai à la gorge, et je me mis à lui secouer vigoureusement la tête contre un mur» ${ }^{86}$. Le châtiment que Baudelaire inflige à ce pauvre vieil homme représente un geste cruel voire sadique, mais qui au fond a une visée perlocutoire, celle d'éveiller en lui sa dignité jusqu'alors réprimée et de l'inciter à exercer favorablement toutes les représailles nécessaires contre tout agresseur : "le malandrin décrépit se jeta sur moi, me pocha les deux yeux, me cassa quatre dents, et, avec la même branche d'arbre, me battit dru comme plâtre. Par mon énergique médication, je lui avais donc rendu l'orgueil et la vie. " ${ }^{87}$

Il en va de même pour Le joujou du pauvre où le monde de l'indigent paraît hégémonique et idéalisé. Ce crescendo triplé : «agaçait, agitait et secouait » anticipe la fonction actantielle d'un clan prédestiné à la révolte. A l'instar du poème intitulé Assommons les pauvres, la gradation

http://www.bibebook.com/files/ebook/libre/V2/baudelaire_charles_-

_le_spleen_de_paris.pdf, le 29/6/2020

${ }^{85}$ Il en va de même pour Le joujou du pauvre où Baudelaire considère le désir de faire l'aumône aux pauvres comme un acte humiliant, ainsi il réduit les enfants à l'état bestial pour se procurer du seul prétexte leur permettant de recevoir le don. Cf., Supra la comparaison des enfants pauvres à des chats. Epistémologie qui transcende l'ère baudelairienne pour présager la spéculation d'Anatole France qui envisage l'aumône comme avilissant pour celui qui la reçoit et celui qui la fait. Cf, FRANCE, Anatole, Monsieur Bergeret à Paris. Histoire contemporaine, Bibebook, 1901, p.109, consulté sur le site :

http://www.bibebook.com/files/ebook/libre/V2/france_anatole_monsieur_b ergeret_a_paris.pdf, le 13/7/2020

86 BAUDELAIRE, Charles, Assommons les pauvres, Op.cit., p.115

${ }^{87}$ Ibid.., pp.114-115

123 
ascendante amorce par le sadisme et débouche sur la rébellion.

Soulignons d'autre part que ce joujou emprisonné dans une boîte grillée incarne une scène qui miroite l'état réel de l'enfant engouffré dans la pauvreté et dans la soumission. Il s'agit de l'identification du sujet au figuratif. Le jouet assume un travail dual entre figurer et effacer. Le rat vivant est un joujou qui gomme la dualité entre le ludique et le réel. La plupart des jouets frôle le monde réel trivial de la nature et de la chair. A l'opposé du joujou en verroteries, le rat connote l'instinct de vie qui rassemble les individus. Quant à la symbolique du rat connu pour animal rongeur, elle représente la vengeance, la destruction et l'autoflagellation. Freud n'a-til pas expliqué que l'homme aux rats ${ }^{88}$ incarne la culpabilisation d'un névrosé tourmenté par une dette qu'il a toujours su qu'il lui était facile de s'acquitter $?^{89}$ Il en va de même pour Le joujou du pauvre qui accentue les troubles, les préoccupations et les dettes ${ }^{90}$ du monde servile. Selon le célèbre psychologue, cet animal réputé impur et fouillant les entrailles de la terre, revêt une connotation phallique et anale, qui le relie à la notion de richesses et d'argent. ${ }^{91}$ Cette phase phallique succède prospectivement à la période de latence des enfants à qui le poète laisse inférer l'idée de la révolte. ${ }^{92}$ Origine de la peste, le rat a, pourtant, un pouvoir palliatif de

88 Un cas de névrose obsessionnelle qu'a consulté Freud en 1909. Cf., https://www.larousse.fr/encyclopedie/divers/1_Homme_aux_rats/183417, consulté le 9/7/2020. Baudelaire, quant à lui, était écrasé par les dettes avant son exil volontaire en Belgique en 1864.

${ }^{89}$ Cf., GOLDBERG, Jacques, Op.cit., p.13

${ }^{90}$ Les vraies dettes des démunis consistent dans leur responsabilité de bannir le joug.

${ }^{91}$ Cf., CHEVALIER, Jean et GHEERBRANT, Alain, Op.cit., p.802

${ }^{92}$ Cf., Supra la phase prépubertaire où Baudelaire semble insuffler la dignité aux pauvres. 
مجلة الدراسات التربوية والانسانية ـ كلية التربية ـ جامعة دمنهور ـ المجلد الثانى عشر - العدد الرابع - لسنة 0202

guérison. ${ }^{93}$ L'anagramme de rat est donc art. Il revivifie à la fois la lumière et le langage d'où l'assimilation du jeu d'enfant à l'esthétique poétique comme le met en cause Freud:

« tout enfant qui joue se comporte en poète, en tant qu'il se crée un monde à lui, ou, plus exactement, qu'il transpose les choses du monde où il vit dans un ordre nouveau tout à sa convenance. ${ }^{94}$

Ainsi, l'enfant pauvre semble ébranler le monde fortuné. Et c'est grâce à l'esthétique du poète transmettant aux jeunes les idées subversives, que la conscience du pauvre s'éveillerait, pour rétablir un nouveau monde où son homologue et lui-même seraient l'objet d'un rêve de perfection. Théorie baudelairienne qui semble puiser ses sources dans l'étude communiste de Karl Marx, laquelle réfute toute discrimination de classe sociale. ${ }^{95}$

Du fait, alors que le pauvre est celui "qui ne peut ni donner ni rendre", la scène canonique du don s'estompe car la fortune proviendrait du mendiant. Le joujou offre une image paradoxale et controversée du réel. Le pauvre est donc le vrai actant qui vient en aide au moi du poète dont le fantasme trace les contours du nouveau monde car c'est à l'enfant

${ }^{93}$ Ce joujou semble jouxter le mal et le bien, le déplaisir et le plaisir pour ainsi accentuer le dogme baudelairien du juste-milieu et de l'équilibre psychique.

${ }^{94}$ FREUD, Sigmund, La création littéraire et le rêve éveillé, Op.cit., p.5

95 Marx précise que lorsque le capital devient une propriété commune appartenant à tous les clans sociaux, "il n'y a que le caractère social de la propriété [personnel] qui soit transformé. Elle perd son caractère de classe. » MARX, Karl, Le manifeste du parti communiste, Bibebook, 1895, consulté sur :

http://www.bibebook.com/search/978-2-8247-1115-7, le 3/5/2020, p.20

125 
pauvre de se délibérer de son joug dans le réel. Le plus que parfait «avaient tiré » dans la phrase : "Les parents, par économie sans doute, avaient tiré le joujou de la vie ellemême » reflète l'absence parentale lors de la phase phallique et l'engagement de l'enfant à l'action. Le joujou tiré de la vraie vie accentue l'idée de la subversion du monde fictif en un cosmos réel. Baudelaire semble adopter la théorie de Rousseau qui trouve la perfection édénique dans la vie primitive précisant que «[...] la nature voulait ainsi égaliser les choses, en donnant aux esprits la fertilité qu'elle refuse à la terre $\gg^{96}$

Le dénouement semble rompre toutes les barrières et ce, via la nouvelle osmose qui jouxte les deux enfants formant des images de modèles masculins. Preuve en est la phrase : "Et les deux enfants se riaient l'un à l'autre fraternellement C'est avec ce groupe que l'enfance trouve d'ores et déjà l'essentiel de ses plaisirs au sein d'un véritable «Moi de groupe » remplaçant la mère perdue ${ }^{97}$. Cependant cette fraternité serait marquée par la parité de deux forces menaçantes en témoigne le segment phrastique : «des dents d'une égale blancheur» qui est co-occurrente avec l'expression «montrer ses dents » accentuant la contrariété du monde réel.

A l'instar des Dioscures Pollux et Castor ${ }^{98}$ dans la mythologie grecque, l'enfant pauvre et l'enfant riche se veulent des frères inséparables et représentent deux figures

${ }^{96}$ ROUSSEAU, Jean-Jacques, Discours sur l'origine et les fondements sur l'inégalité parmi les hommes, Edition électronique, les Échos du Maquis, (1754), 2011, p.29, consulté sur le site: https://philosophie.cegeptr.qc.ca/wp-content/documents/Discours-surlin\%C3\%A9galit\%C3\%A9-1754.pdf le 7/7/2020

${ }^{97}$ Cf., MENDEL, Gérard, Op.cit., p.183, Baudelaire semble compenser «l'interdit premier » par la fraternité.

${ }^{98}$ SCHMIDT, Joël, Op.cit., p.60 
superposées. Sous l'égide de la fraternité, Pollux partage son immortalité avec son frère Castor, il en va de même pour l'enfant pauvre qui communie avec son confrère en échangeant le rire. De plus, ce monde que Baudelaire dépeint paraît sourdement parallèle à la franc-maçonnerie ${ }^{99}$ dont la fraternité est la propre devise. Or, si l'architecture est la pierre de cette organisation, le cosmos baudelairien est fondé sur l'art et la poésie qui pourraient bousculer le réel. Baudelaire le créateur tisse un canevas narratif où il assigne une mission à son interlocuteur tout en se gardant dans l'angle mort pour subvertir la problématique de l'aumône qu'il considère comme répréhensible. Via les joujoux incarnant les fantasmes du poète, la cohorte désignée comme un sujet intérimaire, conçoit et les idées subversives et la théorie du juste-milieu de Baudelaire. L'enfant riche, quant à lui, épouse le nouveau dogme du héros lui-même, le destinataire du credo baudelairien. L'enfant pauvre serait donc le mandataire voué à rassembler les deux pierres du paradis perdu où l'être ou plutôt l'étant l'emporte sur le paraître et où la fraternité dit le dernier mot dans la trame narrative. Cette démarche baudelairienne semble concilier les moi partiels du poète qui croit à la double postulation de l'homme : l'une vers le bien et l'autre vers le mal.

\section{Annexe :}

\section{Destinateur}

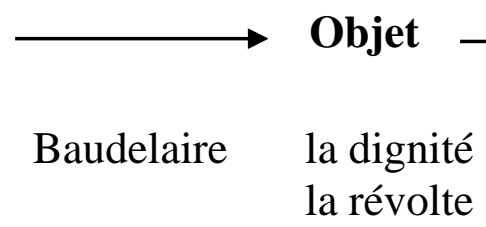

Destinataire

Les enfants et les futurs pauvres

99 Les maçons dési : BENHAMOU, Phili]

127

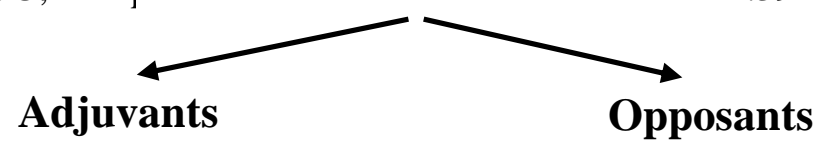

Le fantasme baudelairien, le

Le paraître et les don du sujet, l'idéologie du apparences 


\section{Bibliographie sélective:}

\section{Corpus:}

-BAUDELAIRE, Charles, Le joujou du pauvre, in Morale du joujou de l'essence du rire, la bibliothèque numérique romande, 1853-1869, pp.34, consulté sur:

https://ebooks-bnr.com/ebooks/pdf4/baudelaire_joujou_essence_rire.pdf le $20 / 5 / 2020$

\section{D'autres Ouvrages de Charles Baudelaire:}

BAUDELAIRE, Charles, Assommons les pauvres, in Le spleen de Paris, Bibebook, pp.114-116, consulté sur: http://www.bibebook.com/files/ebook/libre/V2/baudelaire_charles_le_spleen_de_paris.pdf, le 29/6/2020

III.Ouvrages critiques, linguistiques, psychanalytiques, philosophiques:

-BENHAMOU, Philippe et HODAPP, Christopher, La Francmaçonnerie pour les nuls, First Editions, 2008

-BERGEZ (D.), GERAUD (V.), RODRIEUX (J.J), Vocabulaire de l'analyse littéraire, Dunod, Paris, 1994 
مجلة الدراسات التربوية والانسانية ـ كلية التربية ـ جامعة دمنهور ـ المجلد الثانى عشر - العدد الرابع - لسنة 0202

- DIEZ, Verónica, «Le jeu chez l'enfant comme lecture et figuration d'un invisible ", in Recherches en Psychanalyse [en ligne], 12/2011, mise en ligne le 22 décembre 2011

-FOUREZ, Florence, «Secret de Polichinelle », in Le point.fr, 8/11/2011 consulté sur: https://www.lepoint.fr/debats/secret-depolichinelle-08-11-2011-1394132_2.php, le 21/5/2020

-FRANCE, Anatole, Monsieur Bergeret à Paris. Histoire contemporaine, Bibebook, 1901, p.109, consulté sur le site: http://www.bibebook.com/files/ebook/libre/V2/france_anatole__monsieur_bergeret_a_paris.pdf, le 13/7/2020

-FRANCESCHI, Elisabeth, «A gorge dénouée : le vide, entre la mort et la vie », Le Bulletin Freudienne n ${ }^{\circ} 41-42$ Février 2003, consulté en ligne sur:http://www.association-freudienne.be/pdf/bulletins/40BF41.04Franceschi.pdf, , le 3/5/2020

-FREUD, Sigmund:

-Au-delà du principe de plaisir, document produit en version numérique par Gemma Paquet, Classiques des sciences sociales, Edition électronique, Québec, Macintosh, (1920), 2002, consulté sur le site: http://classiques.uqac.ca/classiques/freud_sigmund/essais_de_psychanal yse/Essai_1_au_dela/Au_dela_principe_plaisir.pdf, le 27/3/2020

-Le rêve et son interprétation, document produit en version numérique par Samir Jemel, les Classiques des sciences sociales, Edition électronique, Québec, Macintosh, (1921), 2015, Chicoutimi, Québec, consulté sur le site: http://classiques.uqac.ca/classiques/freud_sigmund/reve_et_son_interpre tation/le_reve_et_son_interpretation.pdf, le 23/5/2020

-La création littéraire et le rêve éveillé, document produit en version numérique par Jean Marie Tremblay, les Classiques des sciences sociales, Edition électronique, Québec, Macintosh, (1933), 1971, p.7, consulté sur le site:

http://classiques.uqac.ca/classiques/freud/04_creation_litteraire/creation _litteraire.pdf,le 27/4/2020

-Le moi et le ça, document produit en version numérique par Gemma Paquet, les Classiques des sciences sociales, Edition électronique, Québec, Macintosh, 2002, consulté sur le site: 
http://classiques.uqac.ca/classiques/freud_sigmund/essais_de_psychanal yse/Essai_3_moi_et_ca/Freud_le_moi_et_le_ca.pdf, le 27/6/2020

- GARRIGUES, Pierre, Poétiques du fragment, KLINCKSIECK, Esthétique, paris, 1995

-GOLDBERG, Jacques, La culpabilité: axiome de la psychanalyse, PUF, Nouvelles voix en psychanalyse, Paris, 1985

-GREIMAS, Algirdas Julien, La sémantique structurale, PUF, Formes sémiotiques, Paris, (1986), 2007

-JOUVE, Vincent, L'effet-personnage dans le roman, Puf écriture, Paris, 1992

-LALO, Vanessa, Le vide en psychanalyse, consulté sur:http://vanessalalo.com/wp-content/uploads/2011/12/Le-Vide-en-

Psychanalyse.pdf

le $3 / 5 / 2020$

-MARX, Carl, Le manifeste du parti communiste, Bibebook, 1895, consulté sur : http://www.bibebook.com/search/978-2-8247-1115-7, le $3 / 5 / 2020$

-MENDEL, Gérard, La psychanalyse revisitée, La découverte/Poche, Paris, 1998

-MESSINGER, Joseph, Le langage des gestes pour les Nuls, FirstGründ, Paris, 2009

-PIGNOL, Claire, pauvreté et fausse richesse chez J.J. Rousseau, Cahiers d'économie politique, 2010, n59, pages 45 à 68, consulté sur: https://www.cairn.info/revue-cahiers-d-economie-politique-2010-2page- 45. htm, le $3 / 5 / 2020$

-ROUSSEAU, Jean-Jacques, Discours sur l'origine et les fondements sur l'inégalité parmi les hommes, Edition électronique, les Échos du Maquis, (1754), 2011, consulté sur le site : https://philosophie.cegeptr.qc.ca/wp-content/documents/Discours-surlin\%C3\%A9galit\%C3\%A9-1754.pdf le 7/7/2020

\section{Dictionnaires:}


مجلة الدراسات التربوية والانسانية ـ كلية التربية ـ جامعة دمنهور ـ المجلد الثانى عشر - العدد الرابع - لسنة 0202

BOUCRAND-HECQUET, Paul, Dictionnaire étymologique des noms propres d'hommes, Victor Sarlit, Paris, 1868, consulté sur le site: http://gallica.bnf.fr/ark:/12148/bpt6k65497229, le 25/12/2017

CHEVALIER, Jean et GHEERBRANT, Alain, Dictionnaire des symboles, Robert Laffont, Bouquins, Paris, (1969), 1982

-KURTH, Hanns, Dictionnaire des rêves de A à Z, France Loisirs, Paris, 1977, p.211 consulté sur:

http://ekladata.com/1Dj_10Y2_eJFI99NAflZdFi9_Vg/Dictionnaire-DesReves-De-A-a-Z.pdf, le 13/5/2020

MOIRE, Tristan-Frédéric, Images et symboles du rêve, Lanore, Paris, 2008

SCHMIDT, Joël, Dictionnaire de la Mythologie grecque et romaine, Larousse, Paris, 1985

http://www.dictionnaire-reve.com/interpretation-reve/2341, consulté le $8 / 7 / 2020$

\section{Webographie:}

https://www.larousse.fr/encyclopedie/divers/1_Homme_aux_rats/183417 , consulté le $9 / 7 / 2020$

-http://arithmomancie.exoteric.fr/numerologie/signification-deslettres/lettre-t/article622.html, consulté le 17/5/2020

-http://www.ma-numerologie-gratuite.com/lettres/lettre-V.html, consulté le $17 / 5 / 2020$

-https://www.dol-celeb.com/objets/poupee-vaudou/, consulté le $13 / 6 / 2020$

-http://www.1voyance.org/interpretation-reve/themes/les-couleurs-dansles-reves/, consulté le 14/6/2020

-https://1001symboles.net/symbole/sens-de-chardon.html, consulté le $18 / 6 / 2020$ 
